\title{
Article \\ Elevated proportions of activated NK cells at diagnosis predict a favorable prognosis in glioblastoma patients
}

\author{
Dominik Lobinger ${ }^{1,2}$, Jens Gempt ${ }^{3}$, Wolfgang Sievert ${ }^{1,2}$, Melanie Barz ${ }^{3}$, Sven Schmitt ${ }^{1,2}$, Huyen \\ Thie Nguyen ${ }^{1,2}$, Stefan Stangl ${ }^{1,2}$, Caroline Werner ${ }^{1,2}$, Fei Wang ${ }^{1,2}$, Zhiyuan Wu ${ }^{1,2}$, Hengyi Fan ${ }^{1,2}$, \\ Hannah Zanth ${ }^{1,2}$, Maxim Shevtsov ${ }^{1,2,3}$, Mathias Pilz ${ }^{1,2}$, Isabelle Riederer ${ }^{5}$, Melissa Schwab ${ }^{1,2}$, \\ Jürgen Schlegel ${ }^{6}$, Gabriele Multhoff ${ }^{1,2, *}$ \\ ${ }^{1}$ Department of Radiation Oncology, School of Medicine, Technical University Munich (TUM), Munich, \\ Germany \\ ${ }^{2}$ Central Institute for Translational Cancer Research, Technical University Munich (TranslaTUM), Munich, \\ Germany \\ ${ }^{3}$ Department of Neurosurgery, School of Medicine, Technical University Munich (TUM), School of Medicine, \\ Munich, Germany \\ ${ }^{4}$ Institute of Cytology of the Russian Academy of Sciences, St. Petersburg, Russia \\ ${ }^{5}$ Department of Neuroradiology, School of Medicine, Technical University Munich (TUM), Munich, Germany \\ ${ }^{6}$ Department of Neuropathology, Technical University Munich (TUM), Munich, Germany \\ * Correspondence: Gabriele Multhoff, TranslaTUM, Klinikum rechts der Isar, Technische Universität \\ München (TUM), Einsteinstr. 25, 81675 Munich, Germany, E-Mail: gabriele.multhoff@tum.de, Tel: +49 89 \\ 4140-4514, Fax: +49 89 4140-4299
}

Simple Summary: Despite multimodal treatment WHO grade IV glioblastoma remains a devastating disease with dismal prognosis. Due to the high metabolic demand aggressive tumors frequently overexpress Hsp70. Depending on its intra- or extracellular localization, Hsp70 either promotes tumor progression or stimulates the immune system. All gliomas are membrane Hsp70positive, and high grade gliomas show a strong nuclear and cytosolic Hsp70 expression. Large necrotic tumor areas are associated with significantly increased Hsp70 serum levels. Elevated frequencies of Hsp70-activated NK cells at diagnosis are associated with a more favorable prognosis in patients with grade IV gliomas.

\begin{abstract}
Despite rapid progress in the treatment of many cancers, glioblastoma remains a devastating disease with dismal prognosis. The aim of this study was to identify immune-related biomarkers that more effectively predict outcome of glioblastoma. Since heat shock protein 70 (Hsp70) and IL-2 are known to increase the expression of activatory NK cell receptors, recognizing aggressive human tumor cells that present Hsp70 on their cell surface, extracellular Hsp70 levels were determined in glioma patients together with activatory NK cell receptors. All gliomas are membrane Hsp70-positive (mHsp70+) and high grade gliomas more frequently show an overexpression of Hsp70 in the nucleus and cytosol. Significantly increased extracellular Hsp70 levels are detected predominantly in glioblastomas with large necrotic areas. Overall survival (OS) is more favorable in patients with low Hsp70 serum levels indicating that a high Hsp70 expression is associated with an unfavorable prognosis. Elevated frequencies of NK cells are associated with a more favorable outcome. Of caution, a glucocorticoid therapy reduces the prevalence of NK cells. In summary, elevated frequencies of Hsp70-reactive NK cells at diagnosis and lower Hsp70 levels predict a more favorable prognosis in glioblastoma patients.
\end{abstract}

Keywords: Hsp70; biomarker; glioblastoma; NK cells; clinical study 


\section{Introduction}

Heat shock protein 70 (Hsp70), the major stress-inducible member of the 70-kDa heat shock protein family is evolutionary conserved and ubiquitously expressed in nearly all subcellular compartments [1]. Under physiological conditions Hsp70 maintains protein homeostasis by preventing protein aggregation, supporting the folding of nascent polypeptides and transporting other proteins across membranes [2]. Stress such as hyperthermia, ischemia, nutrient deficiency or therapeutic interventions strongly upregulate the synthesis of Hsp70. Cytosolic Hsp70 interferes with signaling pathways that affect apoptosis, proliferation and differentiation [2] and as a result, elevated intracellular Hsp70 levels protect tumor cells from apoptosis [3]. Due to their high metabolic demand many aggressive tumor types exhibit an overexpression of Hsp70 which promotes tumorigenesis [4]. Following stress, Hsp70 rapidly translocates into the nucleus and/or interacts with lysosomal membranes in the cytosol to stabilize them [5].

We have previously shown that serum levels of Hsp70 correlate with the viable tumor mass and affect peripheral blood lymphocyte (PBL) compositions and profiles in patients with non-small lung cell cancer (NSCLC) [6]. Extracellular Hsp70 exists in the form of free protein which predominantly originates from dying tumor cells or is bound to exosomes that are actively released by viable tumor cells $[7,8]$.

As part of the innate immune system NK cells are responsible for the first line of defense against infectious diseases and cancer. NK cells release T cell recruiting chemokines including IFN- $\gamma$, TNF$\alpha$. NK cell cytotoxicity is mediated either via granzyme B/perforin, apoptosis receptor interactions and/or antibody dependent cellular cytotoxicity (ADCC) through Fc- $\gamma$ receptors. Their activity is independent of a clonal $\mathrm{T}$ cell receptor and major histocompatibility complex antigens (MHC), but is tightly regulated by the balance between the expression density of activating receptors with a short ITAM and inhibiting receptors with a long ITIM motif [9]. To license NK cells to kill mHsp70+ tumor cells they can be activated by an incubation with full length Hsp70 protein, Hsp70-expressing exosomes [7,8] or a 14-mer Hsp70-peptide TKD (TKDNNLLGRFELSG) derived from the C-terminal substrate binding domain in combination with interleukin 2 (IL-2) $[10,11]$. Due to the smaller size, favorable biodistribution, higher purity and easier GMP-production the Hsp70-peptide TKD is advantageous to recombinant Hsp70 protein for stimulating of NK cells. A pilot [12] and clinical phase I study [13] demonstrated excellent safety profiles of ex vivo TKD/IL-2-activated, autologous NK cells, and patients with advanced NSCLC showed promising clinical responses in a randomized clinical phase II trial after adoptive transfer of ex vivo TKD/IL-2-activated NK cells [14]. Apart from a study in grade IV glioblastoma/astrocytoma patients [15] insight into the expression and localization of Hsp70 in different types of brain tumors and its impact on the prevalence and activity of NK cells is limited. Therefore, intracellular, extracellular and mHsp70 levels were profiled as potential prognostic biomarkers and stimuli for NK cells.

Gliomas predominantly originate in the brain parenchyma. Among the diffuse growing gliomas which are classified according to the WHO classification as grade II, III and IV gliomas, glioblastoma is the most common primary malignant tumor of the central nervous system in adults $[16,17]$. Glioblastoma is treated with surgery, radiation and a temozolomide-based chemotherapy [18]. However, despite this multimodal therapy these patients still have a dismal prognosis with median survival rates of approximately 15 months [18]. Tumor grading, age, isocitrate-dehydrogenase 1 (IDH1) and methylation status of the DNA repair gene O-6-methylguanin-DNA methyltransferase (MGMT) promotor, performance status and extent of resection are considered for predicting clinical outcome $[19,20]$. However, presently only the MGMT promotor status qualifies for a prediction of clinical responses to temozolomide.

The goal of the present study was to identify immune-related biomarkers in the circulation of glioma patients that predict outcome more reliably.

\section{Results}

\subsection{MR imaging and Hsp70 staining of brain tumors}


Clinical characteristics such as WHO grade, age, diagnosis, isocitrate-dehydrogenase 1 (IDH-1) wild type (WT) of all glioma patients are summarized in Table 1.

Table 1. WHO grade, age, diagnosis, isocitrate-dehydrogenase 1 (IDH-1) wild type (wt) of glioma patients.

\begin{tabular}{|l|l|l|l|l|l|l|}
\hline $\begin{array}{l}\text { WHO } \\
\text { grade }\end{array}$ & $\begin{array}{l}\text { median age } \\
\text { [years] }\end{array}$ & $\begin{array}{l}\text { age range } \\
\text { [years] }\end{array}$ & diagnosis & $\begin{array}{l}\text { IDH-1 } \\
\text { wt }\end{array}$ & $\begin{array}{l}\mathrm{n} \\
\text { subgroups }\end{array}$ & $\begin{array}{l}\mathrm{n} \\
\text { total }\end{array}$ \\
\hline II & 30.5 & $24-52$ & oligodendroglioma & 0 & 2 & \\
\hline & & & astrocytoma & 0 & 6 & 8 \\
\hline III & 49.5 & $29-61$ & $\begin{array}{l}\text { anaplastic } \\
\text { oligodendroglioma }\end{array}$ & 0 & 8 & 6 \\
\hline & & & anaplastic astrocytoma & 1 & 66 & 15 \\
\hline IV & 62 & $21-89$ & glioblastoma & 65 & 66 \\
\hline
\end{tabular}

Representative MR images of different brain tumors are shown in Figure 1A. Low grade tumors typically do not show contrast enhancement or necrosis and appear hyperintense on FLAIR images and hypointense on T1-weighted images, whereas glioblastomas show a thick irregular contrast enhancement, central necrosis, and perifocal FLAIR-hyperintensity that represents tumor infiltration and edema. FFPE sections of tumor biopsies were stained immunohistochemically for their intracellular Hsp70 content. Only tumor areas, but not the surrounding tissue were considered for the evaluation. Figure 1B shows 7 representative views of the different staining intensities (low/high) and localizations (nuclear/nuclear+cytosolic) of Hsp70. Table 2 summarizes the data of grade II (n=3), grade III $(n=4)$ and grade IV gliomas $(n=17)$ in a four-by-four analysis. In summary, 2 of 3 grade II gliomas (67\%) were scored as Hsp70 low and 1 of $3(33 \%)$ as high, 1 of 4 grade III gliomas (25\%) were scored as Hsp70 low and 3 of 4 (75\%) as high, and 5 of 17 grade IV gliomas (30\%) were scored as Hsp70 low and 12 of 17 (70\%) as high (Table 2). Hsp70 rapidly translocates into the nucleus upon stress. All lower grade gliomas showed only a nuclear Hsp70 localization, whereas 16 of 17 (94\%) grade IV gliomas exhibited a nuclear+cytosolic Hsp70 localization (Table 2). In general the Hsp70 staining intensity is weaker in lower grade gliomas compared to glioblastomas. Due to the higher amount of Hsp70 in high grade gliomas, Hsp70 is found in the nucleus and cytosol of grade IV gliomas.

Table 2. Correlation of glioma grading (grade II, III, IV) with the Hsp70 staining intensity (low versus high) and Hsp70 localization (nuclear versus nuclear+cytosolic).

\begin{tabular}{|l|c|c|}
\hline WHO grade & $\begin{array}{c}\text { Hsp70 intensity } \\
\text { low }\end{array}$ & $\begin{array}{c}\text { Hsp70 intensity } \\
\text { high }\end{array}$ \\
\hline II & $2 / 3$ & $1 / 3$ \\
& $(67 \%)$ & $(33 \%)$ \\
\hline III & $1 / 4$ & $3 / 4$ \\
& $(25 \%)$ & $(75 \%)$ \\
\hline IV & $5 / 17$ & $12 / 17$ \\
& $(30 \%)$ & $(70 \%)$ \\
\hline \multirow{2}{*}{ WHO grade } & Hsp70 localization & Hsp70 localization \\
& nuclear & nuclear+cytosolic \\
\hline II & $3 / 3$ & $0 / 3$ \\
& $(100 \%)$ & $(0 \%)$ \\
\hline III & $4 / 4$ & $0 / 4$ \\
& $(100 \%)$ & $(0 \%)$ \\
\hline IV & $1 / 17$ & $16 / 17$ \\
& $(6 \%)$ & $(94 \%)$ \\
\hline
\end{tabular}



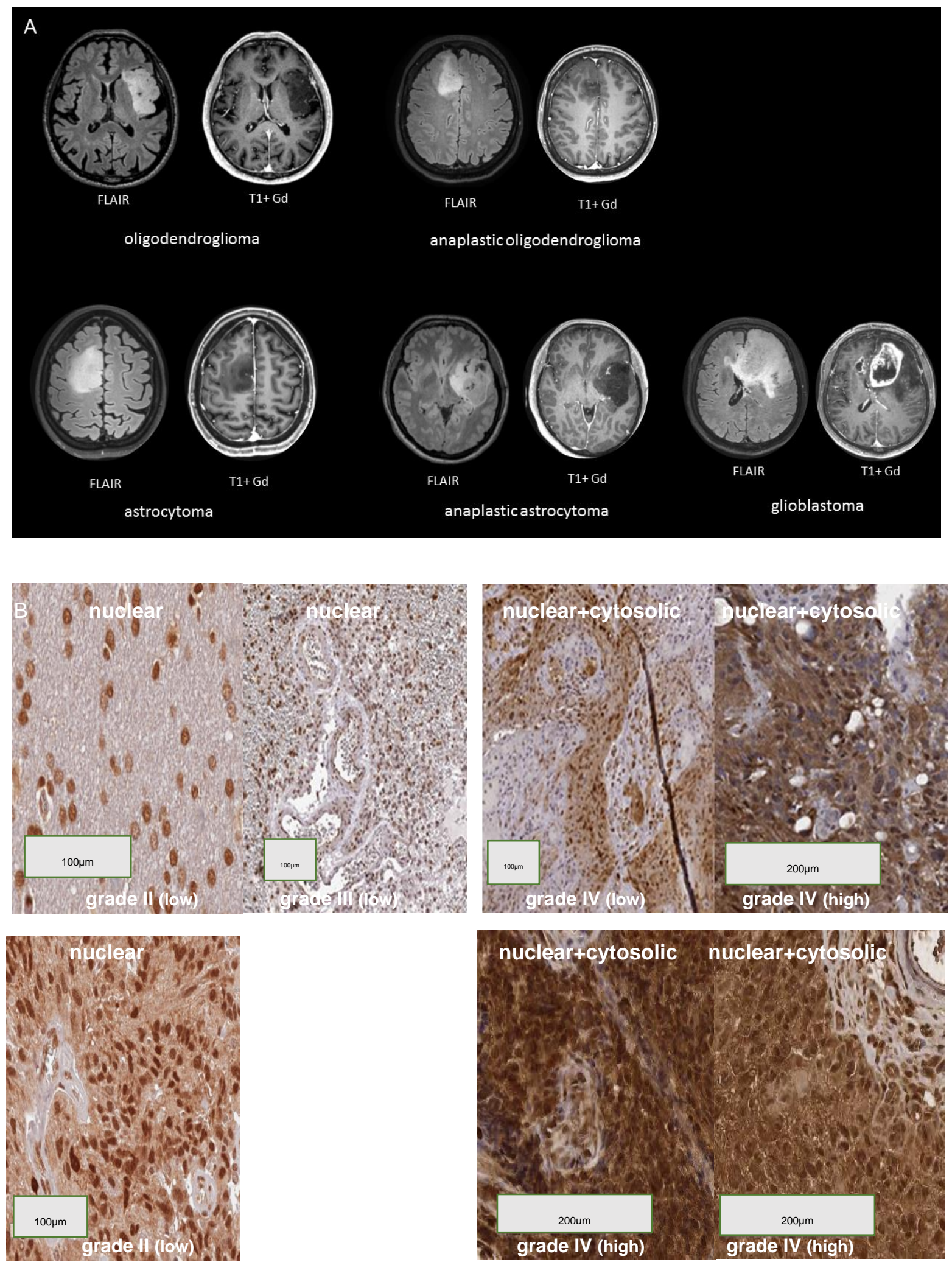

Figure 1. A. Representative MR images of different glioma grades: oligodendroglioma, astrocytoma (grade II), anaplastic oligodendroglioma, anaplastic astrocytoma (grade III), glioblastoma (grade IV). Left, FLAIR images, right, T1 images with Gadolinium (Gd). B. Representative immunohistochemical (IHC) stainings of Hsp70 in tumor sections $(3 \mu \mathrm{m})$ of grade II, III and IV gliomas. Shown are comparisons of nuclear versus nuclear+cytosolic stainings patterns with low or high Hsp70 staining intensity. 


\subsection{Membrane Hsp70 (mHsp70) expression on viable brain tumor cells}

In addition to the cytosolic Hsp70 content, the mHsp70 positivity was determined in isolated, single cell suspensions of freshly resected brain tumors by flow cytometry. Due to the poor viability of brain tumor cells in vitro (20-30\%), the mHsp70 status could be determined only in a total of 37 tumor samples. An intact plasma membrane is key for determining the membrane status of Hsp70 because otherwise a false positive, cytosolic Hsp70 staining will be determined by flow cytometry. The mHsp70 staining intensity appeared to be slightly higher in glioblastomas compared to low grade gliomas. Overall the proportion of $\mathrm{mHsp} 70+$ tumor cells was above $60 \%$ in all glioma grades, but did not differ significantly between the different tumor grades (Figure 2).

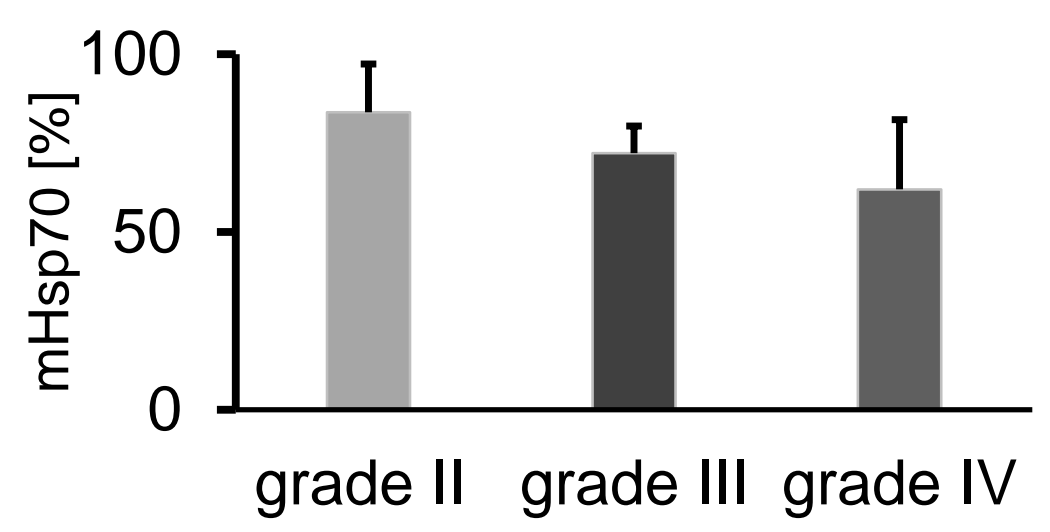

Figure 2. Comparative analysis of the proportion of mHsp70+ tumor cells in grade II ( $n=3)$, grade III $(n=6)$ and grade IV ( $n=28)$ gliomas (Kruskal Wallis; not significant, $n s)$.

\subsection{Extracellular Hsp70 concentrations}

Serum Hsp70 levels were determined in grade II $(n=5)$, grade III $(n=12)$ and grade IV $(n=51)$ patients at first diagnosis using the R\&D ELISA which predominantly detects free Hsp70 originating from dying tumor cells and by an "in-house" Hsp70 ELISA [21] that detects both, free and liposomal Hsp70. As shown in Figure 3A, the median free Hsp70 concentrations in the circulation of patients with grade IV gliomas at diagnosis were significantly higher $(3.48 \mathrm{ng} / \mathrm{ml})$ than in healthy controls $\left(\mathrm{n}=150,2.60 \mathrm{ng} / \mathrm{ml}\right.$, Tukey; $\left.{ }^{*} \mathrm{p}<0.05\right)$. Median serum Hsp70 concentrations in grade II and III glioma patients were $3.14 \mathrm{ng} / \mathrm{ml}$ and $3.34 \mathrm{ng} / \mathrm{ml}$, respectively, but did not differ significantly to that of healthy control donors (Figure 3A). With respect to liposomal Hsp70 which is representing the viable tumor mass in other tumor entities [21], no significant differences were observed in all tumor grades (data not shown).

According to their tumor volumes, patients with grade IV gliomas $(n=44)$ were separated into groups of patients with small $\left(<30 \mathrm{~cm}^{3}\right)$, medium $\left(30-90 \mathrm{~cm}^{3}\right)$ and large $\left(>90 \mathrm{~cm}^{3}\right)$ tumors. The median tumor volumes in patients with small tumors $(\mathrm{n}=6)$ was $9.2 \mathrm{~cm}^{3}$ (range $\left.4.8-26 \mathrm{~cm}^{3}\right)$, in those with medium tumors $(\mathrm{n}=16)$ was $71.7 \mathrm{~cm}^{3}\left(\right.$ range $\left.35.3-81.8 \mathrm{~cm}^{3}\right)$, and in those with large tumors $(\mathrm{n}=22)$ was $140.9 \mathrm{~cm}^{3}$ (range $99-222 \mathrm{~cm}^{3}$ ). As shown in Figure 3B, glioblastoma patients with large tumor volumes had significantly higher median Hsp70 concentrations in the serum $(3.68 \mathrm{ng} / \mathrm{ml}, \mathrm{n}=22)$ than healthy controls $(2.60 \mathrm{ng} / \mathrm{ml}, \mathrm{n}=150)$, as calculated by the Kruskal Wallis test $\left({ }^{*} \mathrm{p}<0.05\right)$, whereas those patients with small and medium tumor volumes did not differ significantly from the healthy control group. 
A

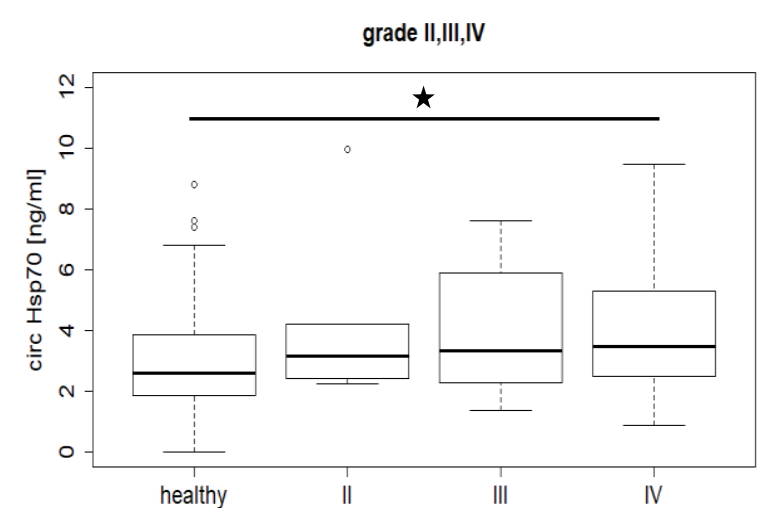

C

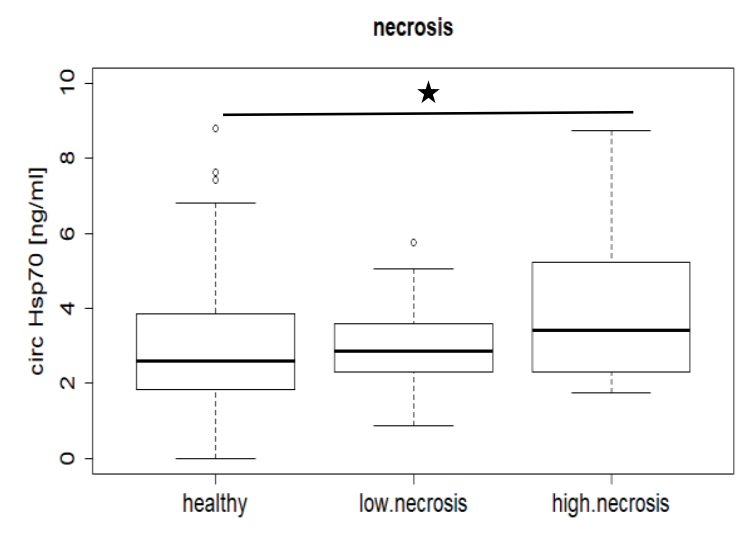

B

D
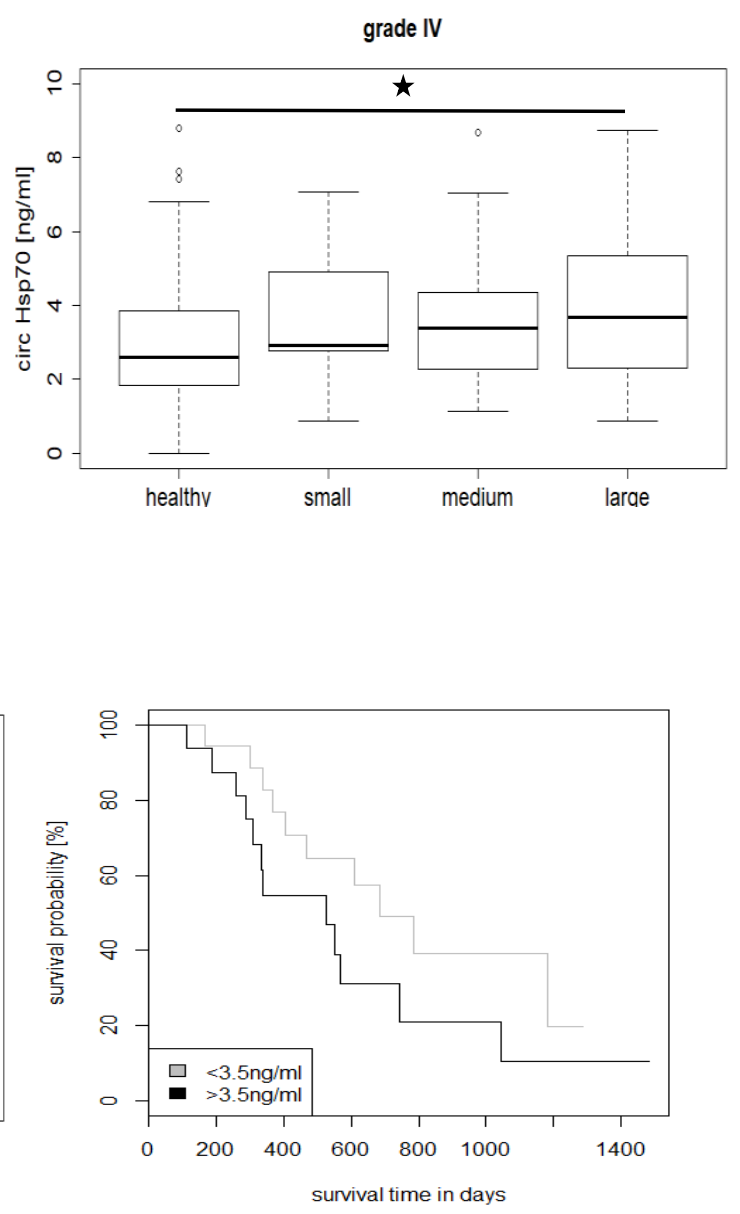

Figure 3. A. Circulating Hsp70 concentrations in healthy controls $(n=150)$ versus grade II $(n=5)$ grade III $(n=12)$ and grade IV $(n=51)$ glioma patients. B. Circulating Hsp70 concentrations in healthy controls $(\mathrm{n}=150)$ versus grade IV glioma patients $(\mathrm{n}=44)$ with small $\left(<30 \mathrm{~cm}^{3}, \mathrm{n}=6\right)$, medium $\left(30-90 \mathrm{~cm}^{3}, \mathrm{n}=16\right)$ and large $\left(>90 \mathrm{~cm}^{3}, \mathrm{n}=22\right)$ tumor volumes, as determined with an ELISA detecting free Hsp70 (Kurskal Wallis; $\left.{ }^{*} \mathrm{p}<0.05\right)$. C. Circulating Hsp70 concentrations in healthy controls $(\mathrm{n}=150)$ versus grade IV glioma $(\mathrm{n}=27)$ with a high $(>10 \%, n=13)$ and low proportion of necrosis $(<10 \%, n=14)$, as determined with an ELISA detecting free Hsp70 (Wilcoxon rank; ${ }^{*} \mathrm{p}<0.05$ ). D. Kaplan-Meier analysis of the overall survival (OS) in glioblastoma patients with Hsp70 serum levels below (n=16) and above $(\mathrm{n}=18)$ a threshold of $3.5 \mathrm{ng} / \mathrm{ml}$ (Logrank; $\mathrm{p}=0.1$ ).

According to MRI, the subgroup of grade IV gliomas $(\mathrm{n}=27)$ was subdivided into a group with a high proportion of necrosis $(>10 \%, n=13)$ and a group with a low proportion of necrosis $(<10 \%$, $\mathrm{n}=14)$. The concentration of free Hsp70 in the circulation $(3.42 \mathrm{ng} / \mathrm{ml})$ in glioblastoma patients with highly necrotic tumors was significantly higher compared to healthy controls $(2.60 \mathrm{ng} / \mathrm{ml}$, Wilcoxon rank Test, ${ }^{*} \mathrm{p}<0.05$ ) (Figure 3C), whereas, that of patients with low tumor necrosis did not differ significantly to healthy controls ( 2.87 versus $2.60 \mathrm{ng} / \mathrm{ml}$ ) (Figure 3C). As expected, liposomal Hsp70 levels did not differ significantly in patients with low and high proportions of tumor necrosis, but were elevated compared to that of healthy controls (data not shown). A Kaplan-Meier analysis of glioblastoma patients whose free Hsp70 serum levels were either below $(n=18)$ or above $(n=16)$ a threshold of $3.5 \mathrm{ng} / \mathrm{ml}$ which distinguishes healthy human individuals from tumor patients revealed an improved OS in patients whose Hsp70 serum levels were below $3.5 \mathrm{ng} / \mathrm{ml}$ ( $\mathrm{p}=0.1$ ) (Figure 3D). 


\subsection{Composition of lymphocyte subpopulations in the peripheral blood of patients with different brain tumors}

The proportions of major lymphocyte subpopulations such as CD19+ B cells, CD3+ T cells, CD3+/CD4+ helper $\mathrm{T}$ cells, CD3+/CD8+ cytotoxic $\mathrm{T}$ cells, CD4+/CD25+/FoxP3+ and CD8+/CD25+/FoxP3+ Tregs, CD3+/CD56+, CD3+/CD94+, CD3+/NKG2D+ NK-like T cells (NKT), CD56+/CD94+, CD3-/CD56+, CD56+/CD69+, CD3-/CD69+, CD3-/NKG2D+, CD3-/NKp30, and CD3/NKp40 NK cells were assessed in the peripheral blood of 75 patients with gliomas at first diagnosis (6 grade II, 13 grade III and 56 grade IV) and healthy controls $(n=15)$. A representative graph of the lymphocyte gating strategy is shown in supplementary Figure 1. The choice of the NK cell receptors was based on the relevance for NK cells to interact with $\mathrm{mHsp70+tumor}$ cells. Neither the percentage of CD19+ B cells, CD3+/CD8+ T cells, CD4+ and CD8+ Tregs nor any of the NK-like T cell subsets differed significantly in patients with gliomas in grade II, III, IV and healthy controls (data not shown). The proportion of CD3+ T cells appeared to be slightly reduced in glioblastoma patients at diagnosis compared to healthy controls (Figure 4A). The percentage of CD4+ T helper cells (Figure 4B) in grade IV glioma patients at first diagnosis, but not that of CD3+/CD8+ cytotoxic T cells (Figure 4C), was significantly lower than in healthy controls, (ANOVA, post-hoc Tukey test, ${ }^{*} \mathrm{p}<0.05$ ). Importantly, the proportion of activated NK cell subsets (CD56+/CD94+, CD3-/CD69+) was significantly greater in glioblastoma patients at diagnosis, as compared to healthy controls (Kruskal Wallis test, ${ }^{*} \mathrm{p}<0.05$ ) (Figure 4D, E). Scatter plots have been included for $\mathrm{T}$ and NK cell markers, including CD3-/NKG2D+, CD3-/NKp30+ and CD3-/NKp46+ NK cell subpopulations, as a supplementary Figure 2. Representative dot blot analysis of CD56+/CD94+, CD3-/CD56+, CD56+/CD69+ and CD3-/CD69+ NK cell subsets of a healthy individual and a grade IV glioblastoma patient are shown in Figure 4F. The proportion of all NK cell subsets as well as the mean fluorescence intensity values (mfi) of CD94 (69 verus 43), CD69 (43 versus 39), and CD56 (70 versus 40) were higher in a grade IV glioma patient compared to a healthy control, respectively.

A

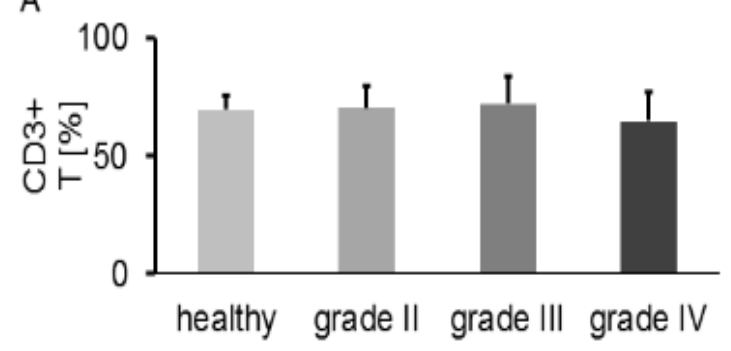

B
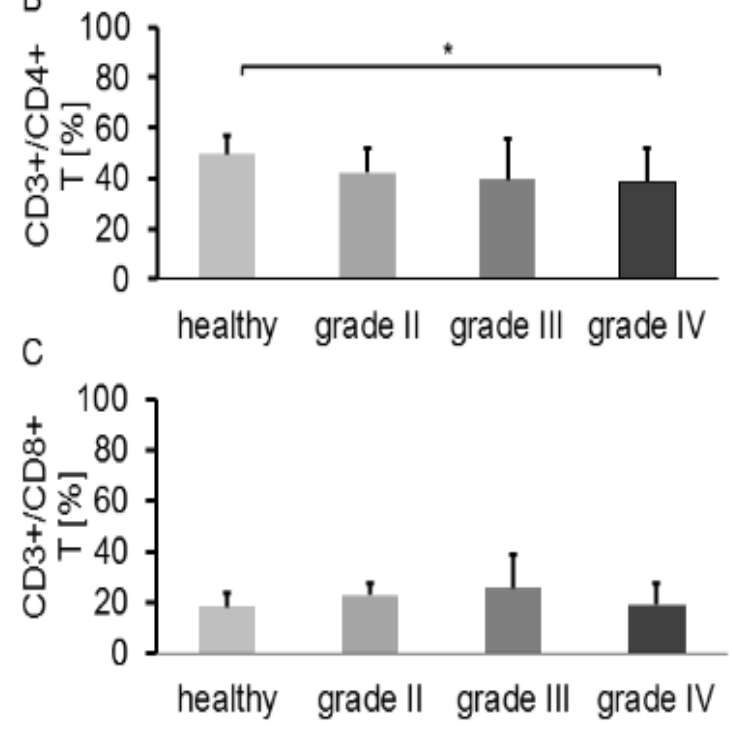

D

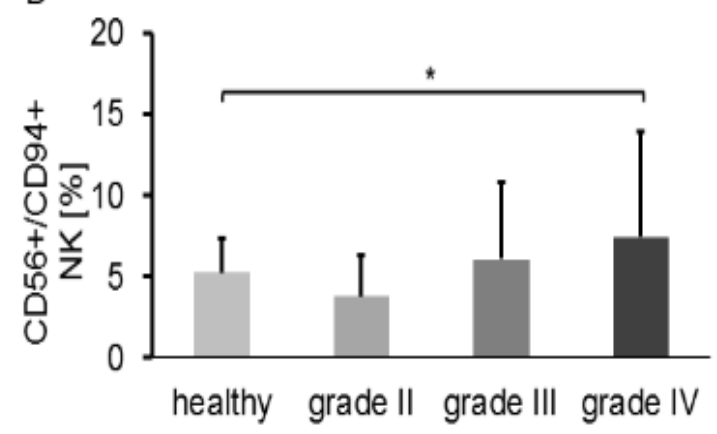

E

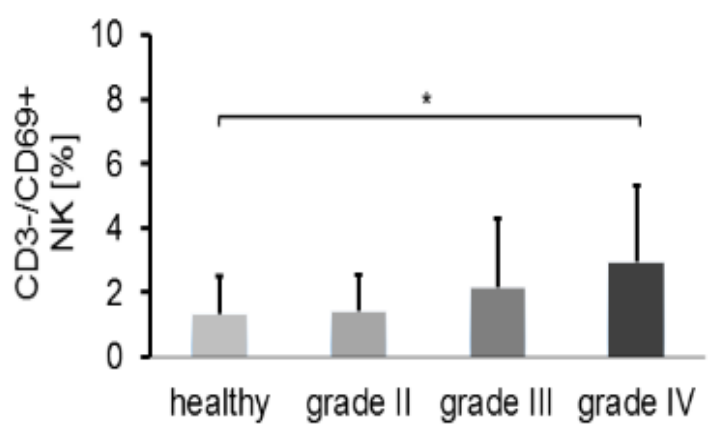



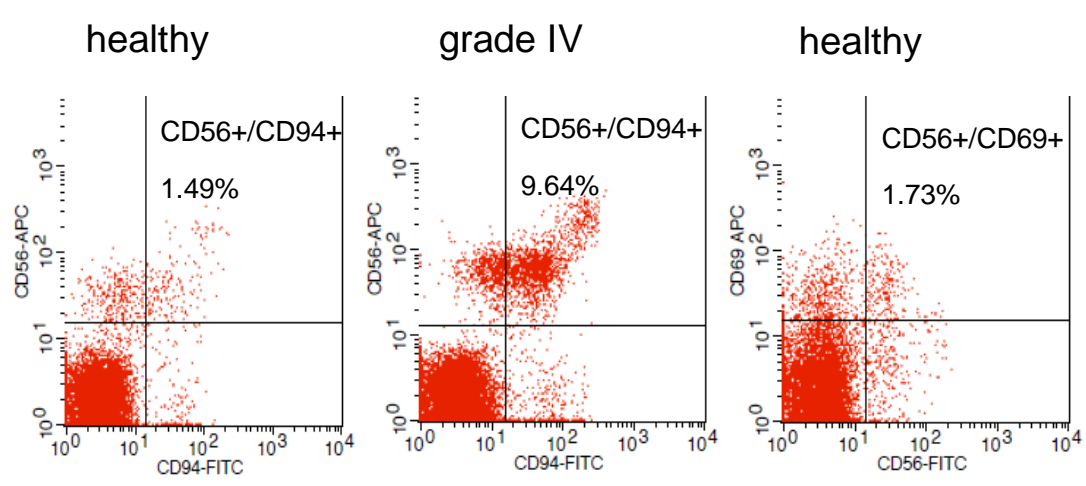

\section{grade IV}
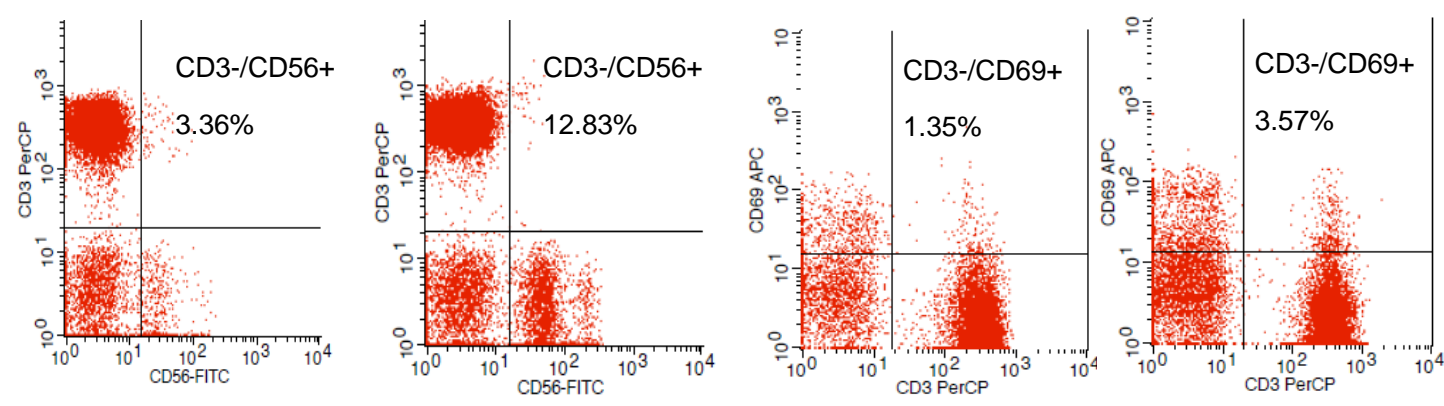

Figure 4. A. The proportion of CD3+ T cells in healthy controls $(n=15)$ versus grade II ( $n=6)$, grade III $(n=13)$ and grade IV gliomas $(n=56)$ in the peripheral blood. $\mathbf{B}$. The proportion of CD3+/CD4+ Thelper cells in healthy controls $(n=15)$ versus grade II $(n=6)$, grade III $(n=13)$ and grade IV gliomas $(n=56)$ in the peripheral blood (Tukey; ${ }^{*} \mathrm{p}<0.05$ ). $\mathrm{C}$. The proportion of CD3+/CD8+ cytotoxic T cells in healthy controls $(n=15)$ versus grade II $(n=6)$, grade III $(n=13)$ and grade IV gliomas $(n=56)$ in the peripheral blood. D. The proportion of CD3-/CD94+ NK cells in healthy controls $(n=15)$ versus grade II $(n=6)$, grade III $(n=13)$ and grade IV gliomas $(n=56)$ in the peripheral blood $\left({ }^{*} p<0.05\right)$. E. The proportion of CD3-/CD69+ NK cells in healthy controls $(n=15)$ versus grade II $(n=5)$, grade III $(n=13)$ and grade IV gliomas $(n=56)$ in the peripheral blood $\left({ }^{*} \mathrm{p}<0.05\right)$. F. Representative dot blot analysis of the proportion of CD56+/CD94+ (1.49\% versus 9.64\%), CD3-/CD56+ (3.36 versus12.83\%), CD56+/CD69+ (1.73 versus $3.30 \%)$ and CD3-/CD69+ (1.35\% versus 3.57\%) NK cells in a healthy control versus a grade IV glioma patient, respectively.

\subsection{Composition of lymphocyte subpopulations in the peripheral blood of healthy donors after ex vivo} stimulation with Hsp70/IL-2 or TKD/IL-2

To mimic potential immunostimulatory effects of circulating Hsp70 in glioblastoma patients, PBL of healthy human donors $(\mathrm{n}=4)$ were stimulated in vitro either with TKD/IL-2 (TKD) or Hsp70/IL2 (Hsp70) [8,10]. Like glioblastoma patients, no significant differences in the composition of CD19+ B cells, CD3+/CD4+ and CD3+/CD8+ T cells, NK-like T cells, and Tregs were detected after stimulation (data not shown). However, the proportion of CD56+/CD94+ NK cells, as represented in Figure 5A, was significantly increased after stimulation with TKD/IL-2 $\left(6.6 \pm 2.08 \%,{ }^{*} \mathrm{p}<0.05\right)$ as compared to unstimulated PBL controls $(2.27 \pm 0.24 \%)$, a similar trend was observed after stimulation with Hsp70/IL-2 (5.81 $\pm 1.49 \%)$. The percentage of CD3-/CD69+ activated NK cells increased significantly after a stimulation with TKD/IL-2 $\left(9.48 \pm 3.85 \%,{ }^{*} \mathrm{p}<0.05\right)$ and Hsp70/IL-2 $\left(10.69 \pm 4.09 \%,{ }^{* *} \mathrm{p}<0.01\right)$ as compared to unstimulated PBL controls (0.27士0.24\%) (Figure 5B). 
A

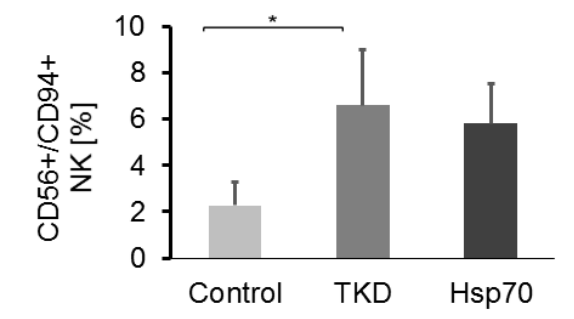

B

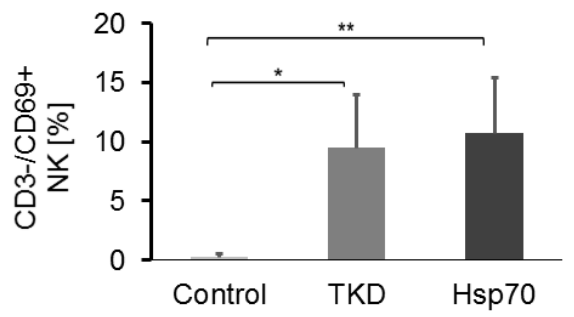

Figure 5. A. The proportion of CD3-/CD94+ NK cells in PBL of unstimulated healthy controls versus Hsp70-peptide TKD/IL-2 or Hsp70/IL-2 stimulated PBL $(n=4)$ (Tukey; $\left.{ }^{*} \mathrm{p}<0.05,{ }^{* *} \mathrm{p}<0.01\right)$. B. The proportion of CD3-/CD69+ NK cells in in PBL of unstimulated healthy controls $(n=4)$ versus Hsp70peptide TKD/IL-2 or Hsp70/IL-2 stimulated PBL $(\mathrm{n}=4)$.

\subsection{Glioblastoma patients without progress exhibit elevated proportions of NK cells at diagnosis}

A comparison of CD19+ B cells, CD3+/CD4+ and CD3+/CD8+ T cells, CD3+/CD4+/CD25+/FoxP3+ and $\mathrm{CD} 3+/ \mathrm{CD} 8+/ \mathrm{CD} 25+/$ FoxP3+ Tregs and NK-like $\mathrm{T}$ cells in glioma patients at diagnosis revealed no significant differences in the prevalence of these cells to that of healthy controls, irrespective of tumor progression at a later time point (data not shown). However, differences were observed with respect to CD56+/CD94+ and CD3-/CD69+ NK cells. Patients with grade III gliomas whose tumors had not progressed after 18 months $(n=9)$ had elevated proportions of CD3-/CD56+ NK cells $(8.5 \pm 5.3 \%$ versus $6.3 \pm 2.8 \%$, data not shown), CD56+/CD94+ NK cells (6.5 $\pm 5.5 \%$ versus $5.3 \pm 3 \%)$ and CD3-/CD69+ NK cells $(2.4 \pm 2.4 \%$ versus $1.6 \pm 1.6 \%)$ compared to patients whose tumors had progressed $(n=3)$ within 18 months (Figure 6A). Similar results were observed in grade IV glioma patients that had not relapsed within 6 months. The proportion of CD3-/CD56+, CD56+/CD94+ and activated CD3-/CD69+ NK cells in patients without progression compared to those who progressed within 6 months was $11.9 \pm 8.9 \%$ versus $9.7 \pm 5.1 \%, 7.1 \pm 5.6 \%$ versus $6.9 \pm 5.2 \%$ and $3.8 \pm 3.3 \%$ versus $2.5 \pm 1.4 \%$, respectively (Figure 6B). Progression was based on Rano criteria for (HGG and LGG) assessed in an interdisciplinary oncological board. Compared to healthy individuals $(n=15)$ the proportion of activated CD3-/CD69+ NK cells at diagnosis was significantly higher in glioblastoma patients who remained progression-free for 6 months $\left({ }^{* *} \mathrm{p}<0.01\right)$ (Figure 6B). As demonstrated in Figure 6C, a shortterm, low dose glucocorticoid therapy which was given to glioblastoma patients with brain edema before surgery drastically decreases the proportion of CD3-/CD56+ NK cells $(13.84 \pm 9.79 \%, \mathrm{n}=33$ to $8.87 \pm 6.53 \%, \mathrm{n}=12$, data not shown), CD3-/CD94+ NK cells $(8.25 \pm 6.25 \%, \mathrm{n}=33$ to $5.47 \pm 4.41 \%, \mathrm{n}=12)$ and CD3-/CD69+ NK cells $(4.56 \pm 5.37 \%, n=33$ to $2.86 \pm 2.22 \%$, $n=12$ ) (Figure 6C). 
A
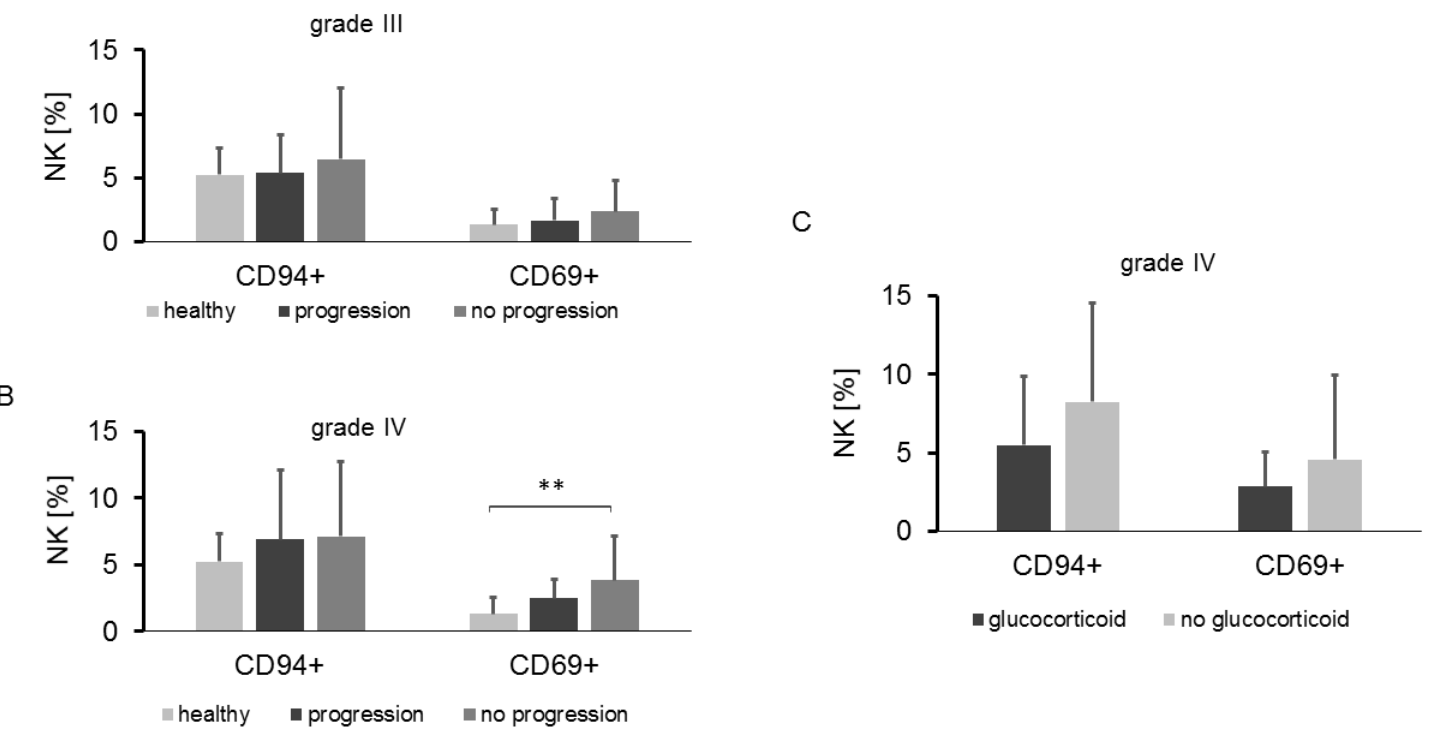

- glucocorticoid no glucocorticoid

Figure 6. A. Percentages of CD3-/CD94+, CD3-/CD69+ NK cells in glioma patients grade III with (n=3) and without tumor progression $(n=9)$ within 18 months after diagnosis compared to healthy controls (Kruskal Wallis; ns). B. Percentages of CD3-/CD94+ and CD3-/CD69+ NK cells in glioma patients grade IV with $(n=10)$ and without tumor progression $(n=27)$ within 6 months after diagnosis compared to healthy controls (Kruskal Wallis; ${ }^{* *} \mathrm{p}<0.01$ ). C. Percentages of CD3-/CD94+ and CD3/CD69+ NK cells in glioma patients grade IV with $(n=12)$ and without $(n=33)$ glucocorticoid treatment (Kruskal Wallis; ns).

Kaplan-Meier curves showing an association of OS with the frequency of CD3-/CD56+ and CD3-/CD94+ NK cells were performed to evaluate the impact of NK cells in prognosis of glioblastoma patients. As illustrated in Figures 7A (CD3-/CD56+) and 7B (CD3-/CD94+) glioblastoma patients with higher NK cell counts have a trend towards a more favorable OS than patients with lower NK cell counts, although the data did not reach statistical significance ( $\mathrm{p}=0.05$; Figure $7 \mathrm{~A}, \mathrm{~B})$.

A

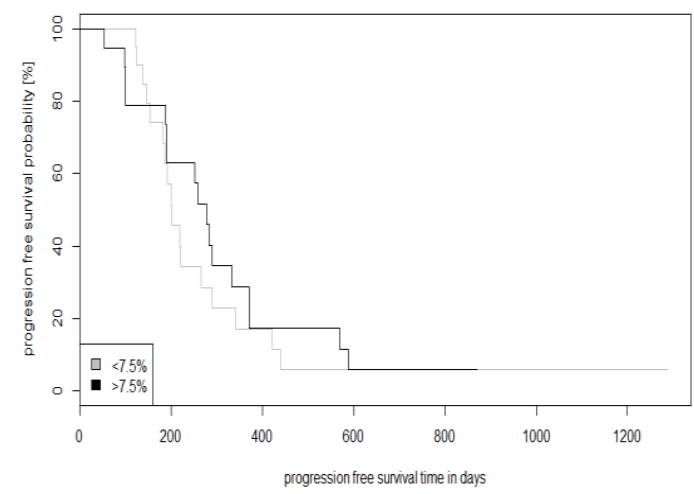

B

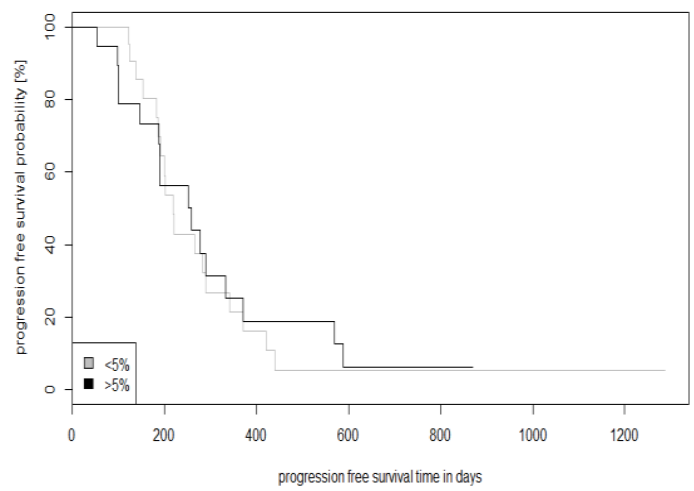

Figure 7. Kaplan-Meier analysis of the overall survival (OS) in glioblastoma patients with the frequency of A. CD3-/CD56+ and B. CD3-/CD94+ NK cells below and above a threshold of 7.5\% and $5 \%$, respectively (Logrank; $\mathrm{p}=0.05)$. 


\section{Discussion}

In 2018 the Nobel prize in Physiology and Medicine was awarded to James P. Allison and Tasuku Honjo for their discovery of immunoregulatory mechanisms mediated by immune checkpoint inhibitors [22], but already years before the interest in immunotherapeutic clinical approaches including immune checkpoint inhibitor blockades [23] and genetically engineered chimeric antigen receptor (CAR)-T/NK cell therapies has attracted the attention of many immunologists [24-27]. However, despite promising results in a number of cancer entities, a significant proportion of patients, including those with brain tumors, do not profit from these immunotherapies [28,29]. Therefore, a better understanding of immunosuppressive and immunostimulatory effects in patients with gliomas is urgently needed. In this study, we aim to identify immune-related biomarkers for predicting of prognosis of glioblastoma by profiling the composition of PBLs and by measuring the expression of intra- and extracellular Hsp70 levels. The concepts were based on the facts that Hsp70 exerts immunostimulatory effects on NK cells or anti-apoptotic activities, depending on its extra- or intracellular localization [30]. Herein, we have shown that high cytosolic levels of Hsp70 are associated with a more aggressive glioma type, but extracellular Hsp70 levels might act as a DAMP to stimulate NK cells. This hypothesis is supported by promising data of phase I and II clinical trials using ex vivo Hsp70 peptide and IL-2 stimulated NK cells to treat patients with advanced colon and lung cancers after radiochemotherapy $[13,14]$. The stimulation of patient-derived, anergic NK cells with Hsp70 peptide plus IL-2, but not with IL-2 alone, significantly enhanced the cytolytic activity of NK cells against membrane Hsp70+ tumor cells [13], and favorable clinical responses in a randomized phase II clinical trial could be attributed to an increased prevalence of activated CD94+ NK cells [14] that are responsible for the interaction with Hsp70 [31]. The increased cytolytic activity of patientderived, Hsp70-activated NK cells can be blocked either by a CD94 specific blocking antibody for NK cells or by an Hsp70 specific antibody for blocking mHsp70 on tumor cells [13]. Previously, we could demonstrate that only MACS purified CD3- NK cells $(>97 \%)$, but not CD3+ T or $\gamma / \delta \mathrm{T}$ cells do recognize mHsp70+ tumor cells and can be stimulated with Hsp70 protein in the absence of cochaperoned immunogenic peptides or TKD and IL-2 [32]. Therefore, other effector cell populations can be excluded for the recognition of mHsp70+ tumor cells. The lysis of mHsp70+ tumor cells by NK cells could be attributed to granzyme B [33]. Following binding and uptake, granzyme B is able to efficiently kill mHsp70+ tumor cells [34]. The production of granzyme B in NK cells of patients with solid tumors [35] is frequently impaired, but can be reconstituted by a stimulation with IL-2 and Hsp70 or TKD [8-10]. Therefore, herein, we studied CD94+ NK cells together with intra-, extracellular and membrane-bound Hsp70 levels.

In contrast to non-malignantly transformed brain tissues (unpublished observation), nearly all highly malignant tumor cells exhibit an upregulated cytosolic Hsp70 expression and a membrane Hsp70-positivity that mediate anti-apoptotic activities and therapy resistance [36,37]. In line with these results, an upregulated nuclear and cytosolic Hsp70 expression was predominantly found in high grade gliomas [38,39], whereas low grade gliomas show a weaker and purely nuclear staining pattern. Due to the limited number of patients with lower grade gliomas, future studies with larger patient cohorts are necessary to assess more detailed the localization of Hsp70 in these tumors.

Compared to healthy controls, significantly elevated serum levels of free Hsp70 were observed in glioblastoma patients with large necrotic tumor areas, but not in low grade gliomas. From this we conclude that extracellular Hsp70 predominantly originates from dying tumor cells [21]. An intact blood-brain-barrier in patients with low grade gliomas might hinder the release of Hsp70 into the circulation of these patients. Liposomal Hsp70 levels [21] predominantly originating from exosomes 
[7] which are assumed to be actively released from viable tumor cells, were higher in grade IV compared to lower grade gliomas, but were not found to be increased in patients with highly necrotic tumors.

An improved OS of glioblastoma patients was associated with Hsp70 serum levels below a threshold of $3.5 \mathrm{ng} / \mathrm{ml}$ which is typically found in healthy individuals. These findings support the hypothesis that the aggressiveness of glioblastomas is associated with high Hsp70 levels.

Extracellular Hsp70 either free or in exosomes [7-9] together with other DAMPs derived from necrotic tumor cells can stimulate the release of pro-inflammatory cytokines including IL-2. We have previously established that Hsp70 in combination with IL-2 stimulates NK cell-mediated immune responses which are mediated by activatory receptors such as CD94/NKG2C can be further enhanced by immune checkpoint inhibition [31,40]. To test the hypothesis that Hsp70-mediated immunostimulation of NK cells might also occur in patients with high grade gliomas, PBLs from healthy donors were stimulated with recombinant Hsp70 or the TKD Hsp70-peptide together with low dose IL-2. This in vitro stimulation resulted in a similar upregulation of the frequency and density of these activatory NK cell receptors such as CD94+ and CD69+ on NK cells to that observed in glioblastoma patients. An upregulated CD94 expression on NK cells correlates with an elevated cytolytic activity against mHsp70+ tumor cells in vitro and in clinical trials [8,12-14]. Although Hsp70 serum levels are increased in the serum of glioblastoma patients the physiological concentrations in the circulation are too low for an efficient NK cell stimulation. Presently we cannot exclude locally increased Hsp70 levels in glioblastoma patients which might have the capacity to activate NK cells.

In line with the literature, patients with high grade gliomas in our study exhibit a decreased frequency of CD3+/CD4+ T cells [41,42]. However, the value of tumor-infiltrating NK cells as a biomarker for gliomas is not completely understood. Although one study denies an involvement, another study indicates that NK cell infiltration into the tumor microenvironment is more common in high grade than low grade gliomas [43,44]. Due to the KIR2DS400101 allele being associated with the capacity to kill glioblastoma cells, NK cell-based immunotherapies have been discussed as an additional treatment option in combination with surgery and radiochemotherapy $[36,45,46]$. Moreover, targeted CAR-NK cell-based immunotherapies are presently tested in preclinical and clinical studies of glioblastoma [47-49]. However, cancer-initiating cells (CICs) escaping immune recognition, elevated Treg, M2 macrophage and MDSC counts in the tumor microenvironment, immunosuppressive factors (i.e., IL-1, TGF- $\beta$, IL-10, arginase I), apoptosis-inducers (i.e., CD95, CD70), tumor hypoxia and immune checkpoint inhibitors are major challenges for immunotherapies [50,51,52]. Future studies are necessary to elucidate the capacity of NK and CAR-NK cells to overcome these immunosuppressive activities in glioblastoma.

A pre-surgical treatment with glucocorticoids reduces the prevalence of activated CD94+ NK cells. Since long-term glucocorticoid therapy has been shown to exert unfavorable effects on the survival of glioblastoma patients treated with RT and/or CT [53] and exert immunosuppressive functions in combination with immune checkpoint inhibitor therapies [54] their use should be considered with caution.

\section{Materials and Methods}

\subsection{Patients}

The study was approved by the local ethical committee of the medical faculty of the Technical University Munich (TUM, \#2403/09) and was conducted in accordance with the Declaration of Helsinki. Written informed consent was obtained from all patients before the start of therapy. EDTAanticoagulated blood (for flow cytometry) and non-coagulated blood (for ELISA) was collected from patients with different types of brain tumors attending in the Department of Neurosurgery. A total of 88 patients were included into the study. According to the WHO classification of Tumors of the Central Nervous System [55] and histopathological analysis (Dpt. Neuropathology), 2 patients were diagnosed as having grade II oligodendroglioma, 6 as having grade II astrocytoma, 8 as having grade III anaplastic oligodendroglioma, 6 as having grade III anaplastic astrocytoma, and 66 patients as 
having grade IV gliomas. The samples were reviewed for this study. All patients were treated with radiotherapy concomitant with temozolomide after surgery according to the Stupp-regimen [18]. Clinical outcome and extracellular Hsp70 levels below and above a cut-off value of $3.5 \mathrm{ng} / \mathrm{ml}$ which was determined by using the Youden-index, at diagnosis were associated with OS in grade IV glioblastoma patients $(\mathrm{n}=34)$ by Kaplan-Meier analysis.

\subsection{Tumor volumetry by magnetic resonance imaging (MRI)}

Pre-operative MRI scans were performed on a 3Tesla MRI scanner (Philips Achieva, Philips Ingenia (Philips Medical Systems, The Netherlands B.V.) or Siemens Verio (Siemens Healthcare, Erlangen, Germany) and analyzed as 3DT2-FLAIR and 3DT1 pre- and post-contrast sequences. Tumor volumes were determined by 2 independent neuroradiologists. MRI sequences (3DT2-FLAIR, 3DT1 post-contrast) were co-registered using a 3D Slicer (www.slicer.org) [56] and tumor volumes were segmented semi-automatically using a freely available software ITK-SNAP (www.itksnap.org) [57] in contrast-enhancing and FLAIR-hyperintense tumor areas.

\subsection{Immunohistochemistry (IHC) and scoring of Hsp70 in brain tumor sections}

A total of 24 formalin-fixed paraffin-embedded (FFPE) sections $(3 \mu \mathrm{m})$ of different brain tumors (Dpt. Neuropathology) were stained for the expression of intracellular Hsp70 content. Briefly, the sections were dewaxed and hydrated in xylol $(9713.3$, Roth) and descending concentrations of ethanol (ethanol absolute, 27694, Fischar $\mathrm{GmbH}$, ethanol 96\% v/v, 27687, Fischar $\mathrm{GmbH}$ ). After heating at 50$60^{\circ} \mathrm{C}$ for $30 \mathrm{~min}$ in citrate buffer (target retrieval solution, $\mathrm{S} 1699$, Dako, 1:10 dilution in $\mathrm{ddH}_{2} \mathrm{O}$ ), sections were washed in $\mathrm{ddH}_{2} \mathrm{O}, \mathrm{H}_{2} \mathrm{O}_{2}(3 \% \mathrm{v} / \mathrm{v})$ and sodium azide $(0.1 \% \mathrm{v} / \mathrm{v})$ in phosphate buffered saline (PBS, D8537-500ML, Sigma Life Science) to block the activity of endogenous peroxidase. Unspecific binding was blocked by rabbit serum ( $5 \% \mathrm{v} / \mathrm{v}$ in antibody diluent, S2022, Dako). The sections were incubated with the Hsp70 monoclonal antibody cmHsp70.1 [58] (multimmune GmbH, Munich, Germany) or a respective IgG1 isotype-matched control antibody (1:500 in antibody diluent, S2022, Dako) at $4^{\circ} \mathrm{C}$ overnight. Antibody binding was detected by incubating horseradish peroxidase (HRP) labelled polymer conjugated with secondary antibodies (Envision+System HRP labelled polymer anti-mouse, K4001, Dako) for $20 \mathrm{~min}$, followed by a Diaminobenzidine chromogen (DAB+substrate buffer, K3468, Dako, DAB+chromogen, K3468, Dako) for exactly 5 min and nucleus was counterstained with haematoxylin and eosin (T865.2, Roth). Sections were embedded and coverslipped in Eukitt quick-hardening mounting medium (Roti-Histokitt 100ml, 6638.1, Roth). Staining of Hsp70-negative (fibroblasts) and Hsp70+ (FaDu tumor cells) was included in each immunohistochemical staining for a better inter-assay comparability of the staining patterns. To compare the staining intensities, the staining procedure was performed absolute identically with identical reagents. Sections were analyzed on an Axio Vison microscope (Carl Zeiss, Jena) using the software ImageScope version 12.3.2.8013. According to the grey scale intensity of the tumor tissue measured by Image J in arbitrary units (AU), the Hsp70 expression was classified into negative, low and high intensity. Nuclear versus nuclear+cytosolic Hsp70 localization was analyzed separately. Scoring of the Hsp70 staining was performed blindly by 2 researchers and 2 neuropathologists.

\subsection{Flow cytometric analysis of mHsp70 expression on viable brain tumor cells}

Freshly aspirated tumor material (Dpt. Neurosurgery) was cut in $1 \mathrm{~mm}^{3}$ pieces, incubated with trypsin for $8 \mathrm{~min}$ and forced through a sterile mesh $(70 \mu \mathrm{m}$ strainer $)$. After resuspension of the single cell suspension in $\mathrm{PBS} / 10 \% \mathrm{v} / \mathrm{v}$ FCS, $5 \times 10^{5}$ cells were incubated with the following fluorescencelabelled antibodies for $30 \mathrm{~min}$ on ice: tube 1: IgG1-FITC /APC (BD Biosciences), tube 2: CD45-APC (Thermo Fisher) and cmHsp70.1-FITC (multimmune GmbH), tube 3: pan-HLA class I-FITC (F5662, Sigma). After two washing steps, 7AAD (BD Biosciences) was added directly before analysis. Only viable, 7AAD-negative tumor cells which are CD45-negative (to exclude lymphocytes), were gated and analyzed using a FACSCalibur ${ }^{\mathrm{TM}}$ flow cytometer (BD Biosciences). The pan-HLA class I antibody 
staining served as a positive control. A minimum of 100.000 events were recorded for each measurement.

\subsection{Measurement of circulating Hsp70 levels}

Serum (S-Monovette $7.5 \mathrm{ml}$ Z, Sarstedt, Nürnbrecht, Germany) was obtained after centrifugation of peripheral blood $(10 \mathrm{~min}, 5000 \mathrm{rpm})$. Aliquots $(300 \mu \mathrm{l})$ were stored at $-80^{\circ} \mathrm{C}$. Hsp70 serum concentrations were determined according to the manufacturer's instructions using the commercial Duo Set Hsp70 ELISA-kit (R\&D Systems, Wiesbaden, Germany) or our "in-house" Hsp70 ELISA [21] which predominantly detects exosomal Hsp70 derived from viable tumor cells.

\subsection{Immune phenotyping of peripheral blood lymphocytes (PBLs)}

Lymphocyte subpopulations in the peripheral blood were profiled by multicolor flow cytometry on a FACSCalibur ${ }^{\mathrm{TM}}$ instrument (BD Biosciences) using the following fluorescence-labelled antibodies: $\mathrm{T}$ cell antibodies CD3-PerCP (BD-345766), CD4-FITC (BD-555346), CD8-FITC/PE (BD347313/BD-555366), NK cell antibodies CD56-FITC/APC (BD-345811/BD-555518), CD94-FITC (BD555888), NKG2D-PE (FAB139P-R\&D Systems), NKp30-PE (PNIM3709-Beckman Coulter), NKp46-PE (PNIM3711-Beckman Coulter), and B cell antibody CD19-PE (555413-BD Biosciences). All stainings included appropriate isotype- and fluorescence-matched control antibodies. After incubation (15 $\mathrm{min}$ ) in the dark at room temperature, cells were washed in PBS/10\% v/v FCS. Red blood cells were lysed by incubating in BD FACS ${ }^{\mathrm{TM}}$ lysing solution (1:9 dilution in $\mathrm{dd}_{2} \mathrm{O}, 349202-\mathrm{BD}$ Biosciences, 10 min). In brief, lymphocytes were gated according to their FSC/SSC characteristics and doublets were excluded. NK and T cells were discriminated based on their CD56 and CD3 expression together with additional NK and T cell markers, as mentioned above.

For regulatory $\mathrm{T}$ cell (Treg) analysis selected CD3+ (CD3-PerCP, BD-345766) T cells were subdivided into CD4+ (CD4-FITC, BD-555346) and CD8+ (CD8-FITC BD-347313) T cells and the percentage of CD25+ (CD25-APC, BD-340907) and FoxP3+ (FoxP3-PE, BD-560046) cells were determined in the CD4+ and CD8+ subpopulation after fixing (buffer $\mathrm{A}, 1: 10$ in $\mathrm{dd}_{2} \mathrm{H}_{2} \mathrm{O}$, 51-9005451BD Biosciences) and permeabilizing the cells (buffer C, 1:50 in buffer A, 51-9005450-BD, $30 \mathrm{~min}$ ). The percentage of positively stained cells was determined within a defined lymphocyte gate.

\subsection{Ex vivo stimulation of peripheral blood lymphocytes with Hsp70/IL-2 or Hsp70-peptide TKD/IL-2}

To mimic potential immunostimulatory effects of circulating Hsp70 in glioblastoma patients, PBL of healthy individuals $(n=4)$ were stimulated either with Hsp70 or Hsp70-peptide TKD together with IL-2 (Novartis Pharma GmbH Nürnberg, 17152.00.00). EDTA-blood (7.5 ml) was collected from healthy volunteers with a median age of 23.5 (range: 22-24 years) from which PBL were separated by Ficoll density gradient centrifugation. After counting, trypan blue-negative, viable cells $\left(5 \times 10^{6}\right)$ were resuspended in RPMI-1640 with L-glutamine, $10 \% \mathrm{v} / \mathrm{v} \mathrm{FCS}$, penicillin G (100 IU/ml) and streptomycin $(100 \mu \mathrm{g} / \mathrm{ml})$ and stimulated either with recombinant Hsp70 $(10 \mu \mathrm{g} / \mathrm{ml})$ and IL-2 $(100 \mathrm{IU} / \mathrm{ml})$ or Hsp70peptide TKD ( $2 \mu \mathrm{g} / \mathrm{ml}$, TKDNNLLGRFELSG, GMP-grade, Bachem AG, Bubendorf) and IL-2 (100 $\mathrm{IU} / \mathrm{ml}$ ) for 5 days $[8,10]$. After stimulation, cells were counted and analyzed by flow cytometry. Viability of PBL after Ficoll separation and after stimulation was always $>95 \%$.

\subsection{Statistics}

The statistical analysis was performed using the programming language $\mathrm{R}, \mathrm{R}$ studio version 3.5.2. Normal distribution was tested by the Shapiro-Wilk normality test. Parametric data were analyzed by ANOVA and post-hoc Tukey tests, non-parametric were analyzed by using the Kruskal Wallis test and Wilcoxon signed-rank test, as appropriate. A value of $\mathrm{p}<0.05$ was considered as representing statistically significant differences. 


\section{Conclusions}

Hsp70 is presented on the plasma membrane of all gliomas and high nuclear and cytosolic Hsp70 levels are associated with high grade gliomas. The present study provides first evidence that elevated proportions of activated CD94+/CD69+ NK cells, which are known the recognize mHsp70+ tumor cells [8], in glioblastoma patients at first diagnosis might be predictive for a more favorable clinical outcome. However, due to the relatively low number of patients the results need to be confirmed in a larger patient cohort.

Author Contributions: DL performed experiments, analyzed data, wrote the manuscript; JG, MB, IR, JS treated patients, provided clinical material and data; WS, SSch, HTN, StS, CW, FW, ZW, HZ, MS, MP, MSch performed experiments, analyzed data; GM conceived and designed the study, analyzed and interpreted the data and reviewed/edited the manuscript. All authors approved the submitted version.

Funding: This research was funded by the Deutsche Forschungsgemeinschaft (SFB824/3, STA1520/1-1, KU 3500/2-1), Bundesministerium für Bildung und Forschung (BMBF-02NUK038A, BMBF-01GU0823), Bundesministerium für Wirtschaft und Energie (BMWi-ZF4320102CS7, BMWi-ZF4320104AJ8)

Institutional Review Board Statement: The study was conducted according to the guidelines of the Declaration of Helsinki, and approved by the Institutional Review Board (or Ethics Committee) of the Klinikum rechts der Isar der Technischen Universität München (TUM) (protocol code 2403/09, 2019).

Informed Consent Statement: Informed consent was obtained from all subjects involved in the study.

Data Availability Statement: The data presented in this study are available on request from the corresponding author. The data are not publicly available due to ethical reasons in a clinical study.

Acknowledgments: The authors want to thank Prof. Dr. Graham Pockley (University of Nottingham, UK) for proof-reading the manuscript and correcting the English.

Conflicts of Interest: Gabriele Multhoff declares a conflict of interest with respect to multimmune GmbH. The company did not have a role in the results or the interpretation of the results but provided the antibody cmHsp70.1. All other authors declare no conflict of interest.

\section{References}

1. Radons J. The human Hsp70 family of chaperones: Where do we stand? CellStressChaperones. 2016, 21:379-404.

2. Mayer MP, Bukau B. Hsp70 chaperones: Cellular functions and molecular mechanisms. Cell Mol Life Sci. 2005, 62:670-684.

3. Beere HM. Death versus survival: Functional interaction between the apoptotic and stress-inducible heat shock protein pathways. J Clin Invest. 2005, 115:2633-2639.

4. Calderwood SK, Khaleque MA, Sawyer DB, Ciocca DR. Heat shock proteins in cancer: Chaperones of tumorigenesis. Trends Biochem Sci. 2006, 31:164-172.

5. Nylandsted J, Gyrd-Hansen M, Danielewicz A, Fehrenbacher N, Lademann U, Hoyer-Hansen M, Weber E, Multhoff G, Rohde M, Jaattela M. Heat shock protein 70 promotes cell survival by inhibiting lysosomal membrane permeabilization. J Exp Med. 2004, 200:425-435.

6. Gunther S, Ostheimer C, Stangl S, Specht HM, Mozes P, Jesinghaus M, Vordermark D, Combs SE, Peltz F, Jung MP, Multhoff G. Correlation of Hsp70 serum levels with gross tumor volume and composition of lymphocyte subpopulations in patients with squamous cell and adeno non-small cell lung cancer. Front Immunol. 2015, 6:556.

7. Gastpar R, Gehrmann M, Bausero MA, Asea A, Gross C, Schroeder JA, Multhoff G. Hsp70 surfacepositive tumor exosomes stimulate migratory and cytolytic activity of NK cells. Cancer Res. 2005, 65:5238-5247.

8. Multhoff G, Mizzen L, Winchester CC, Milner CM, Wenk S, Eissner G, Kampinga HH, Laumbacher B, Johnson J. Heat shock protein 70 (Hsp70) stimulates proliferation and cytolytic activity of NK cells. Exp Hematol. 1999, 27:1627-1636. 
9. Pockley AG, Vaupel P, Multhoff G. NK cell-based therapeutics for lung cancer. Exp Opin Biol Ther. 2020, 20:23-33.

10. Multhoff G, Pfister K, Gehrmann M, Hantschel M, Gross C, Hafner M, Hiddemann W. A 14-mer Hsp70 peptide stimulates NK cell activity. CellStressChaperones. 2001, 6:337-344.

11. Multhoff G, Botzler C, Jennen L, Schmidt J, Ellwart J, Issels R. Heat shock protein 72 on tumor cells: A recognition structure for NK cells. J Immunol. 1997, 158:4341-4350.

12. Kokowski K, Stangl S, Seier S, Hildebrandt M, Vaupel P, Multhoff G. Radiochemotherapy combined with NK cell transfer followed by second-line PD-1 inhibition in a patient with NSCLC stage IIIb inducing long-term tumor control: A case study. SUON. 2019, 195:352-361.

13. Krause SW, Gastpar R, Andreesen R, Gross C, Ullrich H, Thonigs G, Pfister K, Multhoff G. Treatment of colon and lung cancer patients with ex vivo Hsp70-peptide-activated, autologous NK cells: A clinical phase I trial. Clin Cancer Res. 2004, 10:3699-3707.

14. Multhoff G, Seier S, Stangl S, Sievert W, Shevtsov M, Werner C, Pockley AG, Blankenstein C, Hildebrandt M, Offner R, Ahrens N, Kokowski K, Hautmann M, Rodel C, Fietkau R, Lubgan D, Huber R, Hautmann H, Duell T, Molls M, Specht H, Haller B, Devecka M, Sauter A, Combs SE. Targeted NK cell-based adoptive immunotherapy for the treatment of patients with NSCLC after radiochemotherapy: A randomized phase II clinical trial. Clin Cancer Res 2020, 26:5368-5379.

15. Thorsteinsdottir J, Stangl S, Fu P. Guo K, Albrecht V, Eigenbrod S, Erl J, Gehrmann M, Tonn JC, Multhoff G, Schichor C. Overexpression of cytosolic, plasma membrane bound and extracellular heat shock protein 70 (Hsp70) in primary glioblastomas. J Neurooncol. 2017, 135:443-452.

16. Ostrom QT, Bauchet L, Davis FG, Deltour I, Fisher JL, Langer CE, Pekmezci M, Schwartzbaum JA, Turner MC, Walsh KM, Wrensch MR, Barnholtz-Sloan JS. The epidemiology of glioma in adults: A "state of the science" review. Neuro Oncol. 2014, 16:896-913.

17. Ellingson BM, Bendszus M, Boxerman J, Barboriak D, Erickson BJ, Smits M, Nelson SJ, Gerstner E, Alexander B, Goldmacher G, Wick W, Vogelbaum M, Weller M, Galanis E, Kalpathy-Cramer J, Shankar L, Jacobs P, Pope WB, Yang D, Chung C, Knopp MV, Cha S, Van Den Bent MJ, Chang S, Yung WK, Cloughesy TF, Wen PY, Gilbert MR. Jumpstarting Brain Tumor Drug Development Coalition Imaging Standardization Steering C, Consensus recommendations for a standardized brain tumor imaging protocol in clinical trials. Neuro Oncol. 2015, 17:1188-1198.

18. Stupp R, Mason WP, Van Den Bent MJ, Weller M, Fisher B, Taphoorn MJ, Belanger K, Brandes AA, Marosi C, Bogdahn U, Curschmann J, Janzer RC, Ludwin SK, Gorlia T, Allgeier A, Lacombe D, Cairncross JG, Eisenhauer E, Mirimanoff RO. European Organisation For R, Treatment of Cancer Brain T, Radiotherapy G, National Cancer Institute of Canada Clinical Trials G. Radiotherapy plus concomitant and adjuvant temozolomide for glioblastoma. N Engl J Med. 2005, 352:987-996.

19. Kita D, Ciernik IF, Vaccarella S, Franceschi S, Kleihues P, Lutolf UM, Ohgaki H. Age as a predictive factor in glioblastomas: Population-based study. Neuroepidemiology. 2009, 33:17-22.

20. Weller M, Van Den Bent M, Tonn JC, Stupp R, Preusser M, Cohen-Jonathan-Moyal E, Henriksson R, Le Rhun E, Balana C, Chinot O, Bendszus M, Reijneveld JC, Dhermain F, French P, Marosi C, Watts C, Oberg I, Pilkington G, Baumert BG, Taphoorn MJB, Hegi M, Westphal M, Reifenberger G, Soffietti R, Wick W. European Association for Neuro-Oncology Task Force On G. EANO guideline on the diagnosis and treatment of adult astrocytic and oligodendroglial gliomas. Lancet Oncol. 2017, 18:e315e329.

21. Breuninger S, Erl J, Knape C, Gunther S, Regel I, Rodel F, Gaipl US, Thorsteinsdottir J, Giannitrapani L, Dickinson AM, Multhoff G. Quantitative analysis of liposomal heat shock protein 70 (Hsp70) in the blood of tumor patients using an novel lipHsp70 ELISA. CCI. 2014, 5:2-10.

22. Sharma P, Allison JP. Dissecting the mechanisms of immune checkpoint therapy. Nat Rev Immunol. 2020, 20:75-76.

23. Postow MA, Callahan MK, Wolchok JD. Immune checkpoint blockade in cancer therapy. J Clin Oncol. 2015, 33:1974-1982.

24. Guo ZS. The 2018 Nobel prize in medicine goes to cancer immunotherapy. BMC Cancer. 2018, 18:1086.

25. Kruger S, Ilmer M, Kobold S, Cadilha BL, Endres S, Ormanns S, Schuebbe G, Renz BW, D'haese JG, Schloesser H, Heinemann V, Subklewe M, Boeck S, Werner J, Von Bergwelt-Baildon M. Advances in cancer immunotherapy 2019 - latest trends. J Exp Clin Cancer Res. 2019, 38:268. 
26. Akhavan D, Alizadeh D, Wang D, Weist MR, Shepphird JK, Brown CE. CAR-T cells for brain tumors: Lessons learned and road ahead. Immunol Rev. 2019, 290:60-84.

27. Brown MP, Ebert LM, Gargett T. Clinical chimeric antigen receptor-T cell therapy: A new and promising treatment modality for glioblastoma. Clin Transl Immunology. 2019, 8:e1050.

28. Huang B, Zhang H, Gu L, Ye B, Jian Z, Stary C, Xiong X. Advances in immunotherapy for glioblastoma multiforme. J Immunol Res. 2017, 3597613.

29. Goswami S, Walle T, Cornish AE, Basu S, Anandhan S, Fernandez I, Vence L, Blando J, Zhao H, Yadav SS, Ott M, Kong LY, Heimberger AB, De Groot J, Sepesi B, Overman M, Kopetz S, Allison JP, Pe'er D, Sharma P. Immune profiling of human tumors identifies CD73 as a combinatorial target in glioblastoma. Nat Med. 2020, 26:39-46.

30. Multhoff G. Heat shock protein 70 (Hsp70): Membrane location, export and immunological relevance. Methods. 2007, 43:229-237.

31. Gross C, Hansch D, Gastpar R, Multhoff G. Interaction of heat shock protein 70 peptide with NK cells involves the NK receptor CD94. Biol Chem. 2003, 384:267-279.

32. Gross C, Schmidt-Wolf IK, Nagaraj S, Ellwart J, Kunz-Schughart L, Multhoff G. Hsp70-reactivity is associated with increased cell surface density of CD94 and CD56. CSC. 2003, 8:348-360.

33. Gross C, Koelch W, Arispe N, DeMaio A, Multhoff G. Cell surface-bound Hsp70 mediates perforinindependent apoptosis by specific binding and uptake of granzyme B. J. Biol Chem. 2003, 17:4117341181.

34. Shevtsov M, Stangl S, Nikolaev B, Yakovleva L, Marchenko Y, Tagaeva R, Sievert W, Pitkin E, Mazur A, Tolstoy P, Galibin O, Ryzhov V, Steiger K, Smirnov O, Khachatryna W, Chester K, Multhoff G,Gross C, Hansch D, Gastpar R, Multhoff G. Small. 2019, 15:e1900205.

35. Bucklein V, Adunka T, Mendler AN, Issels R, Subklewe M, Schmollinger JC, Noessner E. Progressive NK cell dysfunction associated with alterations in subset proportions and receptor expression in softtissue sarcoma patients. Oncoimmunology. 2016, 5:e1178421.

36. Ciocca DR, Calderwood SK. Heat shock proteins in cancer: diagnostic, prognostic, predictive and treatment implications. CellStressChaperones. 2005, 10:86-103.

37. Murakami N, Kühnel A, Schmid TE, Ilicic K, Stangl S, Braun IS, Gehrmann M, Molls M, Itami J, Multhoff G. Role of membrane Hsp70 in radiation sensitivity of tumor cells. Radiat Oncol. 2015, 10:149.

38. Beaman GM, Dennison SR, Chatfield LK, Phoenix DA. Reliability of Hsp70 (HSPA) expression as a prognostic marker in glioma. Mol Cell Biochem. 2014, 393:301-307.

39. Ceccarelli M, Barthel FP, Malta TM, Sabedot TS, Salama SR, Murray BA, Morozova O, Newton Y, Radenbaugh A, Pagnotta SM, Anjum S, Wang J, Manyam G, Zoppoli P, Ling S, Rao AA, Grifford M, Cherniack AD, Zhang H, Poisson L, Carlotti CG, Jr., Tirapelli DP, Rao A, Mikkelsen T, Lau CC, Yung WK, Rabadan R, Huse J, Brat DJ, Lehman NL, Barnholtz-Sloan JS, Zheng S, Hess K, Rao G, Meyerson M, Beroukhim R, Cooper L, Akbani R, Wrensch M, Haussler D, Aldape KD, Laird PW, Gutmann DH, Network TR, Noushmehr H, Iavarone A, Verhaak RG. Molecular profiling reveals biologically discrete subsets and pathways of progression in diffuse glioma. Cell. 2016,164:550-563.

40. Shevtsov M, Pitkin E, Ischenko A, Stangl S, Khachatryan W, Galibin O, Edmond S, Lobinger D, Multhoff G. Ex vivo Hsp70-activated NK cells in combination with PD-1 inhibition significantly increase overall survival in preclinical models of glioblastoma and lung cancer. Front Immunol. 2019,10:454.

41. Mcvicar DW, Davis DF, Merchant RE. In vitro analysis of the proliferative potential of T cells from patients with brain tumor: Glioma-associated immunosuppression unrelated to intrinsic cellular defect. J Neurosurg. 1992, 76:251-260.

42. Fecci PE, Ochiai H, Mitchell DA, Grossi PM, Sweeney AE, Archer GE, Cummings T, Allison JP, Bigner DD, Sampson JH. Systemic CTLA-4 blockade ameliorates glioma-induced changes to the CD4+ T cell compartment without affecting regulatory T-cell function. Clin Cancer Res. 2007, 13:2158-2167.

43. Stevens A, Kloter I, Roggendorf W. Inflammatory infiltrates and NK cell presence in human brain tumors. Cancer. 1988, 61:738-743.

44. Yang I, Han SJ, Sughrue ME, Tihan T, Parsa AT. Immune cell infiltrate differences in pilocytic astrocytoma and glioblastoma: Evidence of distinct immunological microenvironments that reflect tumor biology. J Neurosurg. 2011, 115:505-511. 
45. Castriconi R, Daga A, Dondero A, Zona G, Poliani PL, Melotti A, Griffero F, Marubbi D, Spaziante R, Bellora F, Moretta L, Moretta A, Corte G, Bottino C. NK cells recognize and kill human glioblastoma cells with stem cell-like properties. J Immunol. 2009, 182:3530-3539.

46. Dominguez-Valentin M, Gras Navarro A, Rahman AM, Kumar S, Retiere C, Ulvestad E, Kristensen V, Lund-Johansen M, Lie BA, Enger PO, Njolstad G, Kristoffersen E, Lie SA, Chekenya M. Identification of a NK cell receptor allele that prolongs survival of cytomegalovirus-positive glioblastoma patients. Cancer Res. 2016, 76:5326-5336.

47. Zhang C, Burger MC, Jennewein L, Genssler S, Schonfeld K, Zeiner P, Hattingen E, Harter PN, Mittelbronn M, Tonn T, Steinbach JP, Wels WS. ERBB2/HER2-specific NK cells for targeted therapy of glioblastoma. J Natl Cancer Inst. 2016, 108.

48. Murakami T, Nakazawa T, Natsume A, Nishimura F, Nakamura M, Matsuda R, Omoto K, Tanaka Y, Shida Y, Park YS, Motoyama Y, Nakagawa I, Yamada S, Tamura K, Takeshima Y, Takamura Y, Wakabayashi T, Nakase H. Novel human NK cell line carrying CAR-targeting EGFRVIII induces antitumor effects in glioblastoma cells. Anticancer Res. 2018, 38:5049-5056.

49. Burger MC, Zhang C, Harter PN, Romanski A, Strassheimer F, Senft C, Tonn T, Steinbach JP, Wels WS. CAR-engineered NK cells for the treatment of glioblastoma: Turning innate effectors into precision tools for cancer immunotherapy. Front Immunol. 2019, 10:2683.

50. Maccalli C, Parmiani G, Ferrone S. Immunomodulating and immunoresisticane properties of cancerinitiating cells: implications for the clinical success of immunotheray. Immunol. Invest. 2017, 46:221-238.

51. Nduom EK, Weller M, Heimberger AB. Immunosuppressive mechanisms in glioblastoma. Neuro-Oncol. 2015, 17:9-14.

52. Multhoff G, Vaupel P. Hypoxia compromises anti-cancer immune responses. Adv Exp Med Biol. 2020, 1232:131-143.

53. Petrelli F, De Stafani A, Ghididni A, Bruschieri L, Riboldi V, Dottorini L, Iaculli A, Zanboni A, Trevisan F. Steroids use and survival in patients with glioblastoma multiforme: a pooled analysis. J Neurol. 2020, https://doi.10.1007/s00415-020-09731-5

54. Kelly WJ, Gilbert MR. Glucocorticoids and immune checkpoint inhibitors in glioblastoma. J Neurooncol. 2020, https://doi.org/10.1007/s11060-020-03439-2

55. Louis DN, Perry A, Reifenberger G, Von Deimling A, Figarella-Branger D, Cavenee WK, Ohgaki H, Wiestler OD, Kleihues P, Ellison DW. The 2016 world health organization classification of tumors of the central nervous system: A summary. Acta Neuropathol. 2016, 131:803-820.

56. Fedorov A, Beichel R, Kalpathy-Cramer J, Finet J, Fillion-Robin JC, Pujol S, Bauer C, Jennings D, Fennessy F, Sonka M, Buatti J, Aylward S, Miller JV, Pieper S, Kikinis R. 3D slicer as an image computing platform for the quantitative imaging network. Magn Reson Imaging. 2012, 30:1323-1341.

57. Yushkevich PA, Piven J, Hazlett HC, Smith RG, Ho S, Gee JC, Gerig G. User-guided 3D active contour segmentation of anatomical structures: Significantly improved efficiency and reliability. Neuroimage. 2006, 31:1116-1128.

58. Stangl S, Gehrmann M, Riegger J, Kuhs K, Riederer I, Sievert W, Hube K, Mocikat R, Dressel R, Kremmer E, Pockley AG, Friedrich L, Vigh L, Skerra A, Multhoff G. Targeting membrane heat-shock protein 70 (Hsp70) on tumors by cmHsp70.1 antibody. PNAS USA. 2011, 108:733-738. 